Journal of Design and Science

\title{
Editorial: Other Biological Futures
}

\author{
Alexandra Daisy Ginsberg, Natsai Chieza
}

Published on: Sep 12, 2018

Updated on: Feb 01, 2019

DOI: $10.21428 / 566868 b 5$ 
Medical devices embedded deep in human flesh. Mushrooms growing designer chairs. Engineered probiotic bacteria colonising the guts of soldiers. Implants; fungal factories; bacteria. All three are "biodesigns", yet each is a product of a very different discipline: biomedical engineering, design, and synthetic biology. Over the last twenty years, each field has in turn claimed the fusing of biology and design as their own. If design is humanity's process for changing present conditions to other, preferred ones (to paraphrase political scientist Herbert Simon), then biodesign-which we broadly define here as the design of, with, or from biology-offers novel perspectives on what change could look like, for ourselves and other living things. Altered or designed by humans, these organisms could populate "other biological futures"; possible futures different to those dictated by our planet's naturally evolved present.

Over the last decade, artist Dr Alexandra Daisy Ginsberg, and designer Natsai Audrey Chieza have been exploring the design of living matter and its potential implications. As editors of this issue of the Journal of Design and Science, we delve into difficulties we see emerging in contemporary biodesign, and open up new directions for investigation.

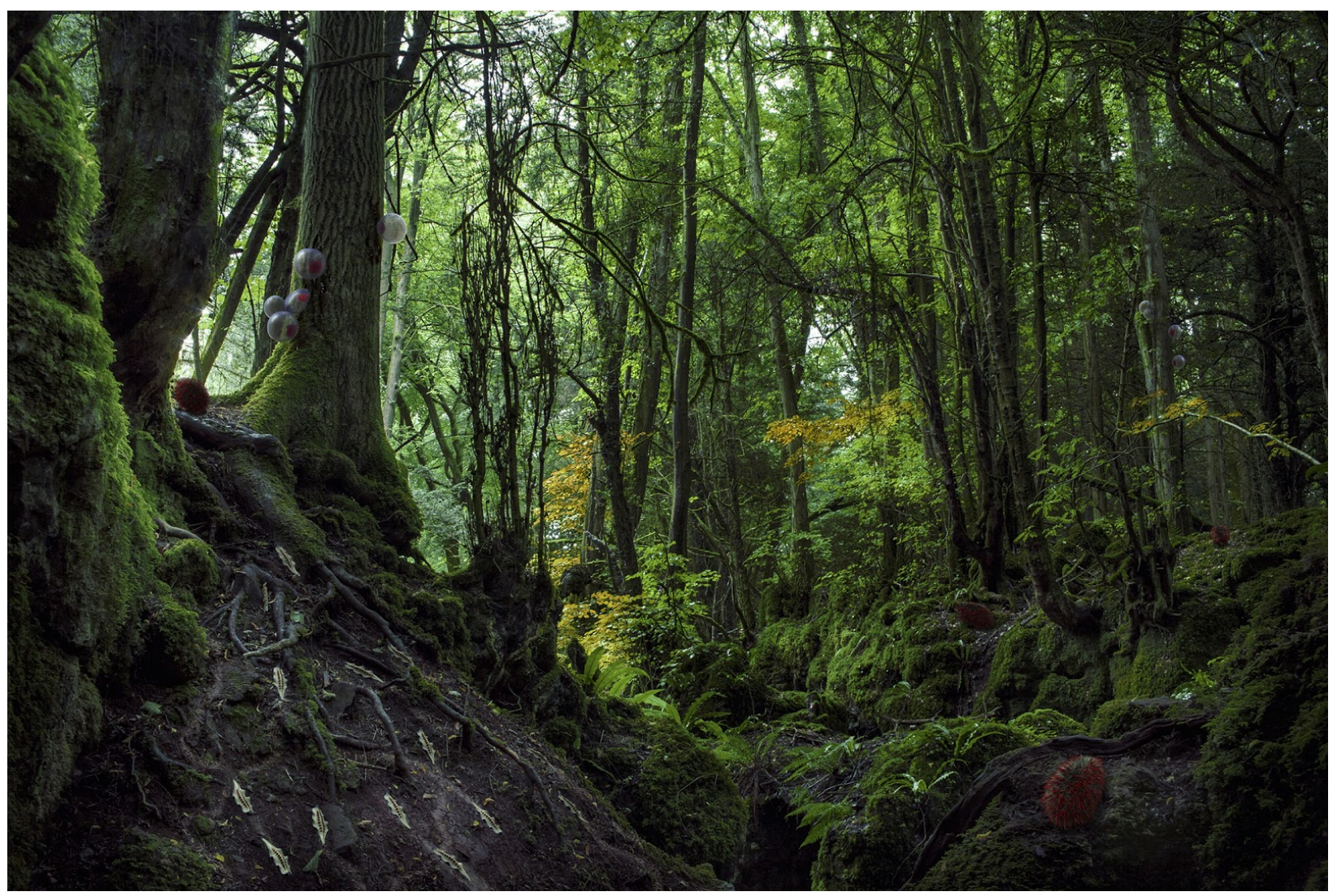

Alexandra Daisy Ginsberg's Designing for the Sixth Extinction (2013-15) uses fiction to explore the real dialogue between the conservation and synthetic biology communities about engineering organisms to save existing, "natural" ones. Credit: Alexandra Daisy Ginsberg. 


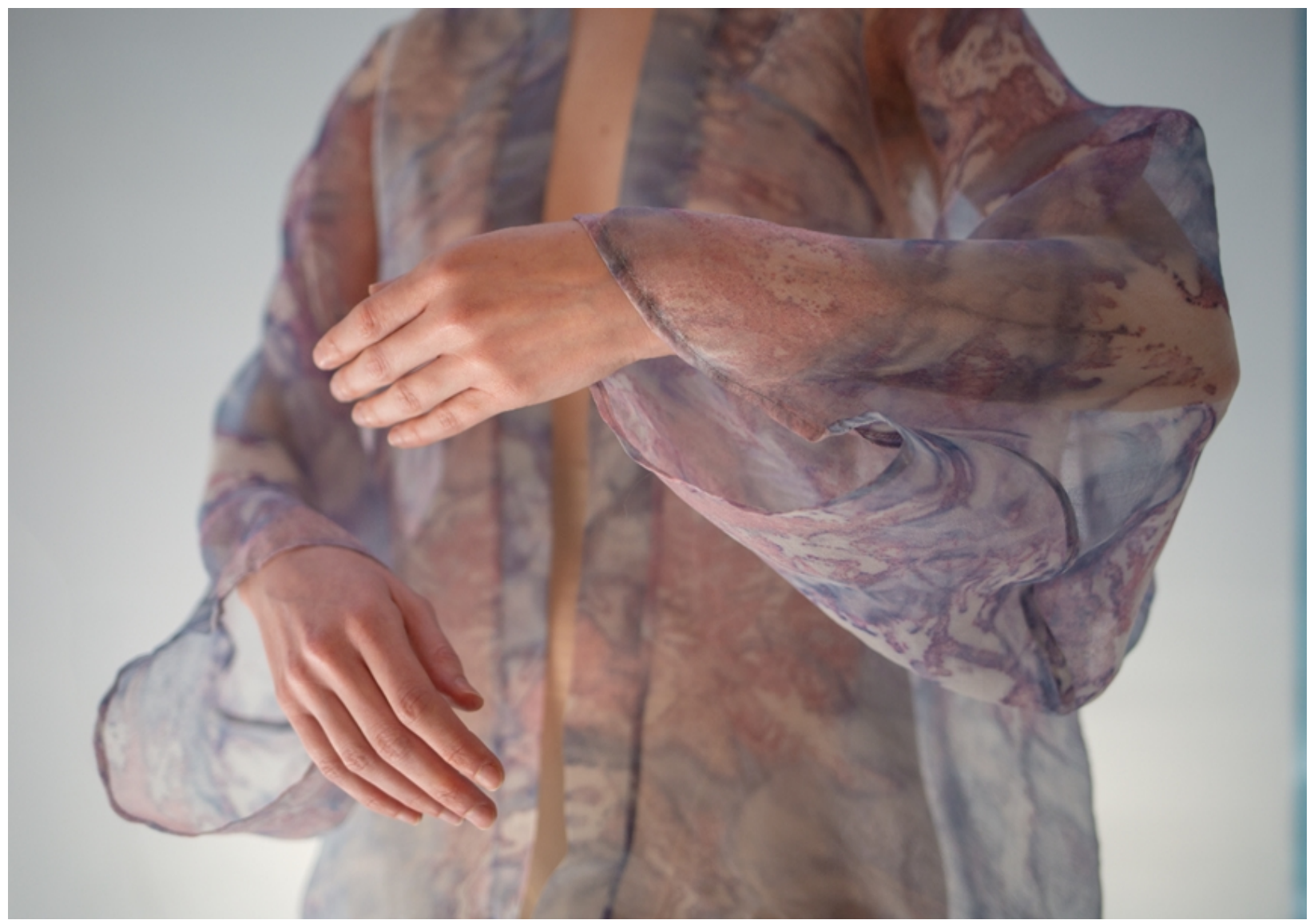

Natsai Audrey Chieza cultures bacteria to print textiles. This garment was specifically designed and pattern cut to be dyed by Streptomyces coelicolor, and made during her residency at Ginkgo Bioworks in 2017. Credit: Natsai Audrey Chieza/Faber Futures.

While specialist fields like synthetic biology - a new approach to genetic engineering - have made the design of biology more precise than ever, the design of, with, or from biology isn't new. From crops to cattle, developing and refining living organisms through selective breeding is a 10,000-year-old practice. Industrial fermentation is a well-honed tool for converting biology into foodstuffs or commodity compounds. Major global industries routinely transform biomass into flat-pack furniture, cotton T-shirts, and vanilla flavourings. However, biodesign fans are today repackaging biodesign, describing it as an ecological remedy, a technological breakthrough, an economic opportunity, and a manufacturing and industrial revolution. For this issue, we question whether biodesign can deliver the accompanying social transformation that those dreams imply, and explore how it might otherwise begin to challenge modern industrial, social, and economic paradigms.

Adopting this more social rather than technological perspective on biodesign allows us to include within it a wide range of activities and people, from traditional to contemporary processes that use low-tech or high-tech methods, practiced by scientists to farmers in labs, factories, studios, and homes. Two questions unite their work: "Can biology do this better?" And, "How will using biology 
change things for the good?" This approach provokes thinking about what "good" biodesign might look like, and what other kinds of potential biological futures could exist, which we hope this issue begins to sketch out.

The growing interest in biodesign is driven by a range of factors. One is rising concern about the ecological and social effects of the Anthropocene, humanity's ever-more-visible impact on Earth, alongside the equally visible failure of earlier green movements to mobilise change. This paradox is increasingly complicating for the contemporary industrial design profession, since capitalism requires a continuous cycle of production and consumption to keep designers in work. World-saving circular design efforts like cradle-to-cradle design were promulgated by some designers and industries in the early 2000s, alongside biomimicry and circular economy efforts that some now consider as essential for meeting the United Nations' Sustainable Development Goals. For designers, this zeitgeist was captured by curator William Myers, who in 2012 titled his popular design book Bio Design, presenting biology as a new, sustainable tool for designers. This burgeoning movement celebrates alternative ways to make things, such as growing biodegradable packaging materials for consumer products. 


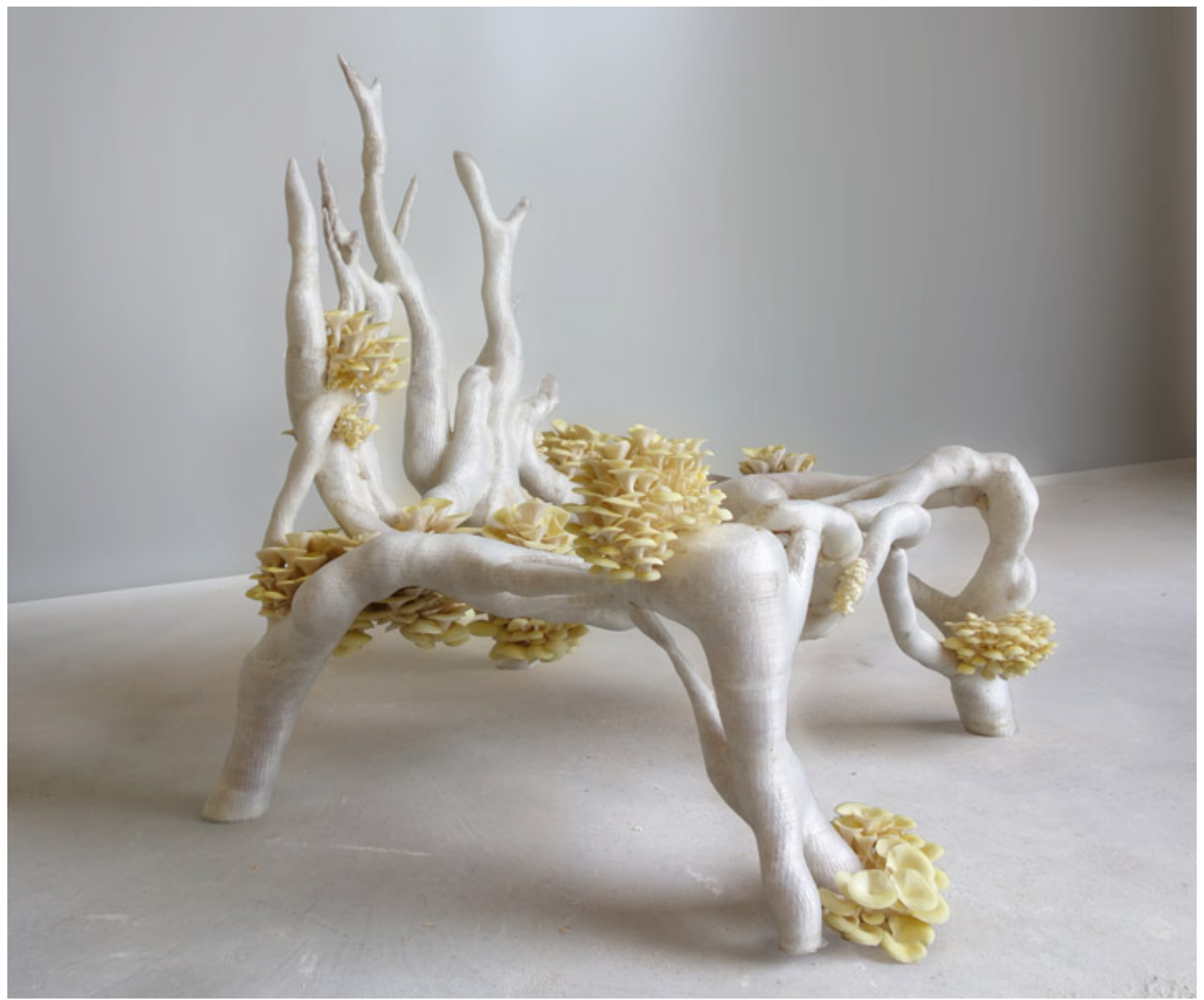

An icon of biodesign for the design world, Erik Klarenbeek's Myceliumchair chair, built from 3D-printed living mycelium. Credit: Studio Klarenbeek \& Dros.

Today, enthusiasts of technosciences like synthetic biology also promise that their technology can help to deliver more sustainable or circular economies. The question "Can biology do it better?" is not just a desire to remediate polluting industries, biodesign also means harnessing self-replicating manufacturing systems that could reinvent industrial processes more widely. 


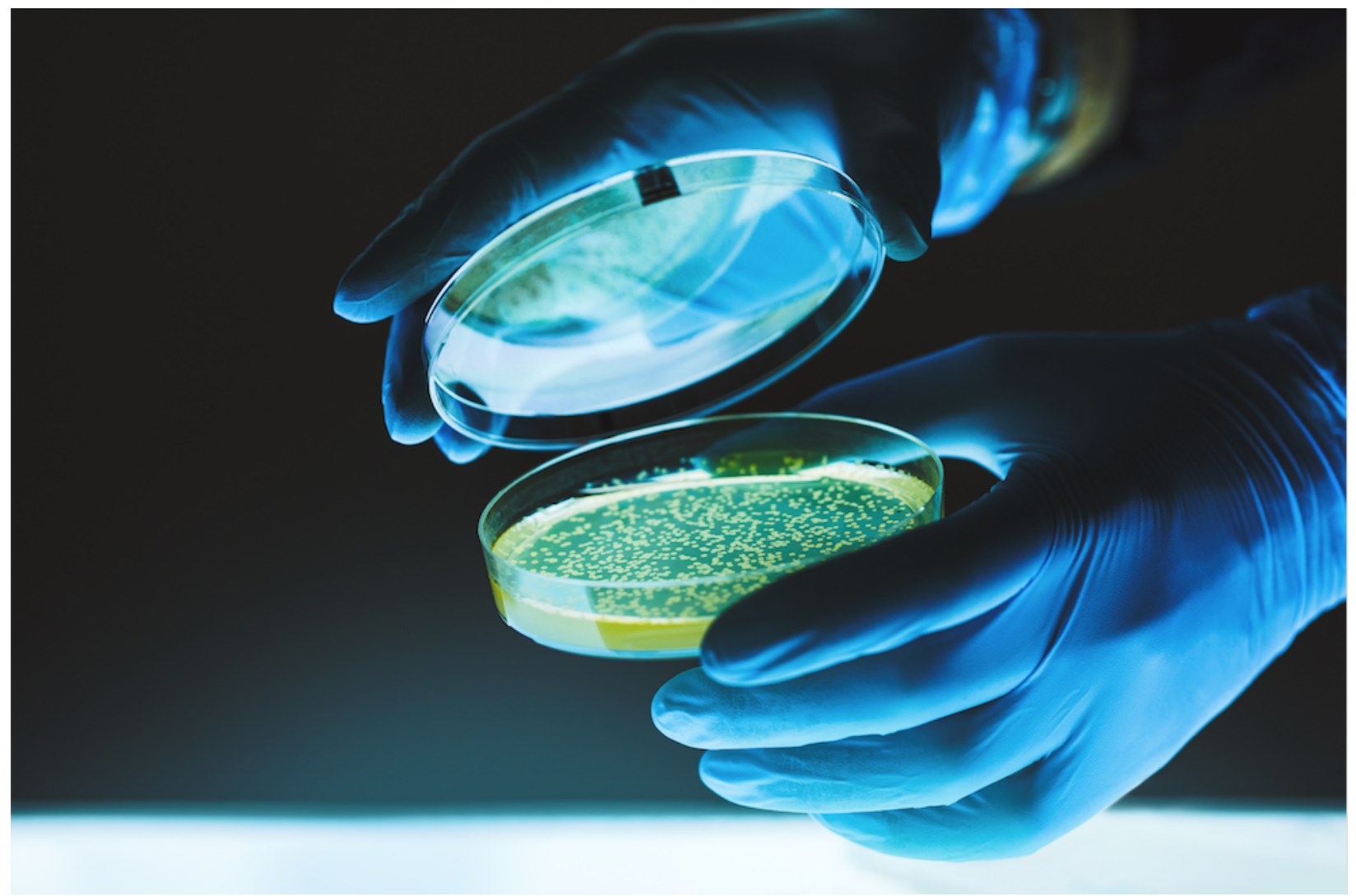

Engineered bacteria at Ginkgo Bioworks' organism foundry. Credit: Ginkgo Bioworks.

In advanced technological societies like the US and UK, the technological, economic, and geopolitical potential of this imagined bioeconomy is driving investment in the sciences, from state to corporate interests. One example is Bolt Threads, a US biotechnology company defining a new paradigm for industrial biodesign. Bolt Threads feeds sugar to its engineered yeast to produce spider silk protein, which is spun into yarn. Presenting itself as a design-led business, Bolt Threads does not look like a typical life science corporation: from its products, to the company it acquired to scale its capabilities, to its partnerships, and its focus on the consumer in the messaging and design of its products.

A glossy PR campaign launched Bolt Threads' first product in 2017, when its limited edition knitted silk tie-the male business wardrobe staple-adorned the necks of male and female influencers, including footballers, actors, and fashion bloggers. Later that year, Bolt Threads purchased the aspirational outdoor lifestyle brand, Best Made Co., purveyor of artisanal axes and designer camping gear, which embrace the imaginary of the American wilderness or frontier explorer. While the acquisition may seem incongruous, Bolt Threads clearly recognised that synthetic biology could do more than simply make "drop-in replacement" molecules that replace petrochemical equivalents: synthetic biology could create value even in the carefully spun fashion market, despite a widespread public aversion to genetically modified organisms. 

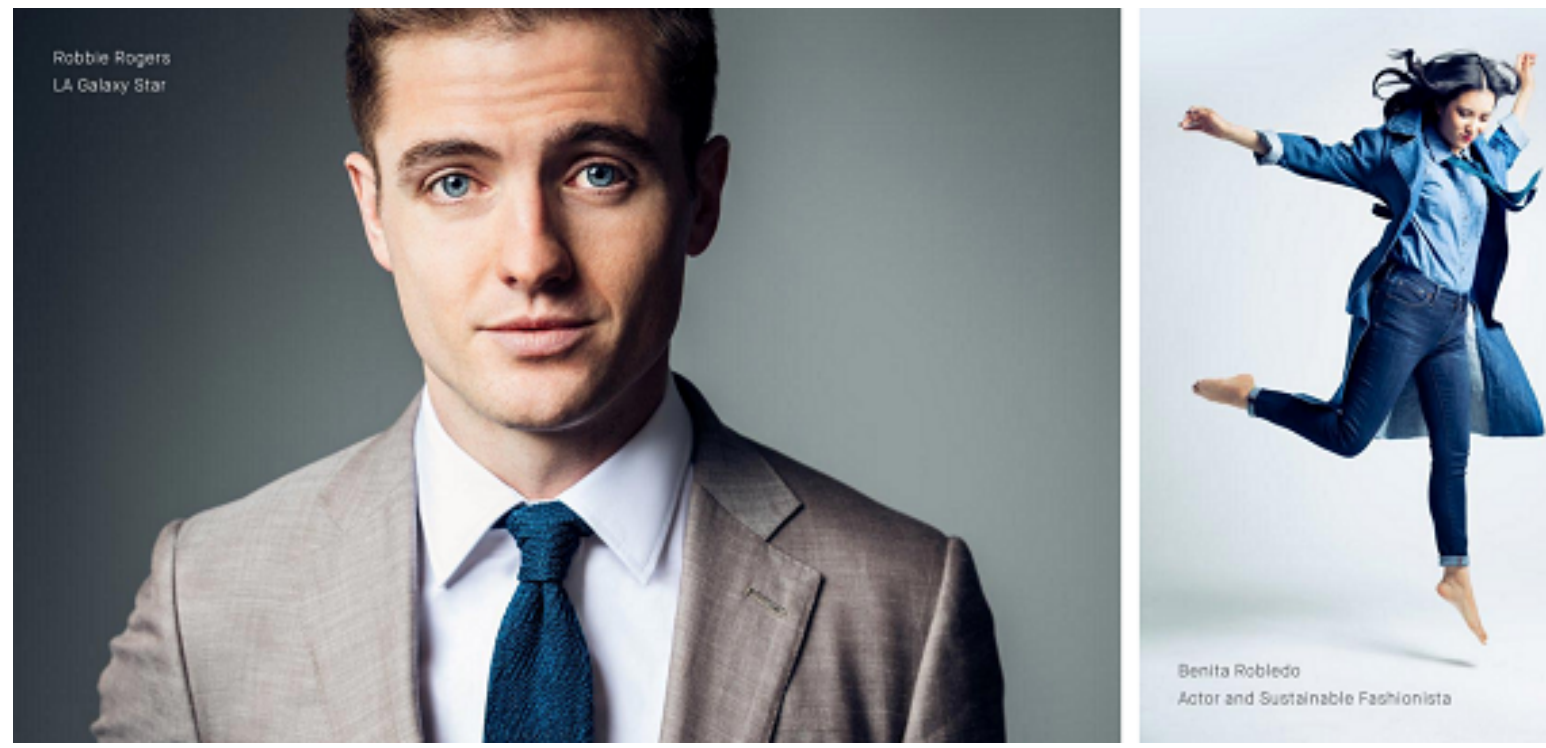

Bolt Threads' campaign images for the launch of their limited edition spider silk tie in 2017. Credit: Bolt Threads.

Best Made's first commercial products under Bolt Threads was a $\$ 198$ wool-spider silk mix beanie hat. Its second, the $\$ 498$ Nyala Knife With Microsilk ${ }^{\mathrm{TM}}$ Handle, demonstrates a silk-based composite as a plastic alternative. Bolt Threads' bioengineered silk has also led to partnerships with $\underline{\text { Stella McCartney. }}$ and Patagonia; both brands that are seen as innovators in sustainable fashion, helping Bolt Threads span the luxury to mass-market continuum. As Bolt Threads transforms its materials into prototypes and limited edition products designed to attract investors and stakeholders, which help build an industry, they inadvertently set the stage for the kinds of products and markets that follow. These early biodesigns test and scale product typologies, methods of production, and distribution models. But as with all designs, they are neither socially, politically, nor environmentally neutral. Silk ties and camping knives, dresses and hiking gear; these objects interact with social values and cultural legacies.

Whether it's Bolt Threads' biosilk plastic, other companies' promises of lab-grown "clean" meat ousting ecologically-damaging factory farming, or the development of less toxic textile-dyeing.processes to mitigate the impact of fast fashion, drop-in replacements serve to make us feel better about our polluting lifestyles. However, what remains unresolved is the space in which these alternatives still operate - the capitalist system that demands continual growth-no matter the costs. The overconsumption that industrial design is predicated upon today is under increasing scrutiny. By designing with biology, start-ups like Bolt Threads can potentially challenge how consumer products are made, their life cycles, and enhance the performance of materials that could improve product lifespans. Scaling these technologies to reduce environmental impact, these new bioindustrialists still need to access the same instruments of capital and consumption that inhibit systemic change. Herein lies the uncomfortable paradox: whose role is it to link new industrial processes with systemic economic, social, and political change? 
If we fail to create this link as new industries emerge, we may simply shift reliance from petrochemicals to other carbon-based feedstocks like sugar for the production of materials, medicines, and commodities. Conceptually, drop-in replacements limit the scope for imagining alternatives, while driving innovation through products alone means that we sidestep decoupling wealth creation from resource consumption. Simply updating traditional products with potentially transformative technologies still reinforces current systems and markets, and their ecological impacts, rather than reinvent them as promised.

At the opposite end of the spectrum from Bolt Threads' pragmatic prototypes lie the seemingly radical biodesign solutions that we encounter in the press, movies, or design exhibitions: growing houses that adapt to our needs, glowing trees that replace street lamps, or bubbling algae-filled façades. In all of these futures technology is supposed to save us from ourselves. But when the intensive requirements of maintaining life may not make a façade greener than a low-tech vernacular architecture, and glowing trees may modify ecosystems in other, potentially harmful ways, are these interventions actually radical? Have we correctly diagnosed the problem, which may be located in our desires, not in our technologies? How do we separate the fantastical imagination from radical re-imagination?

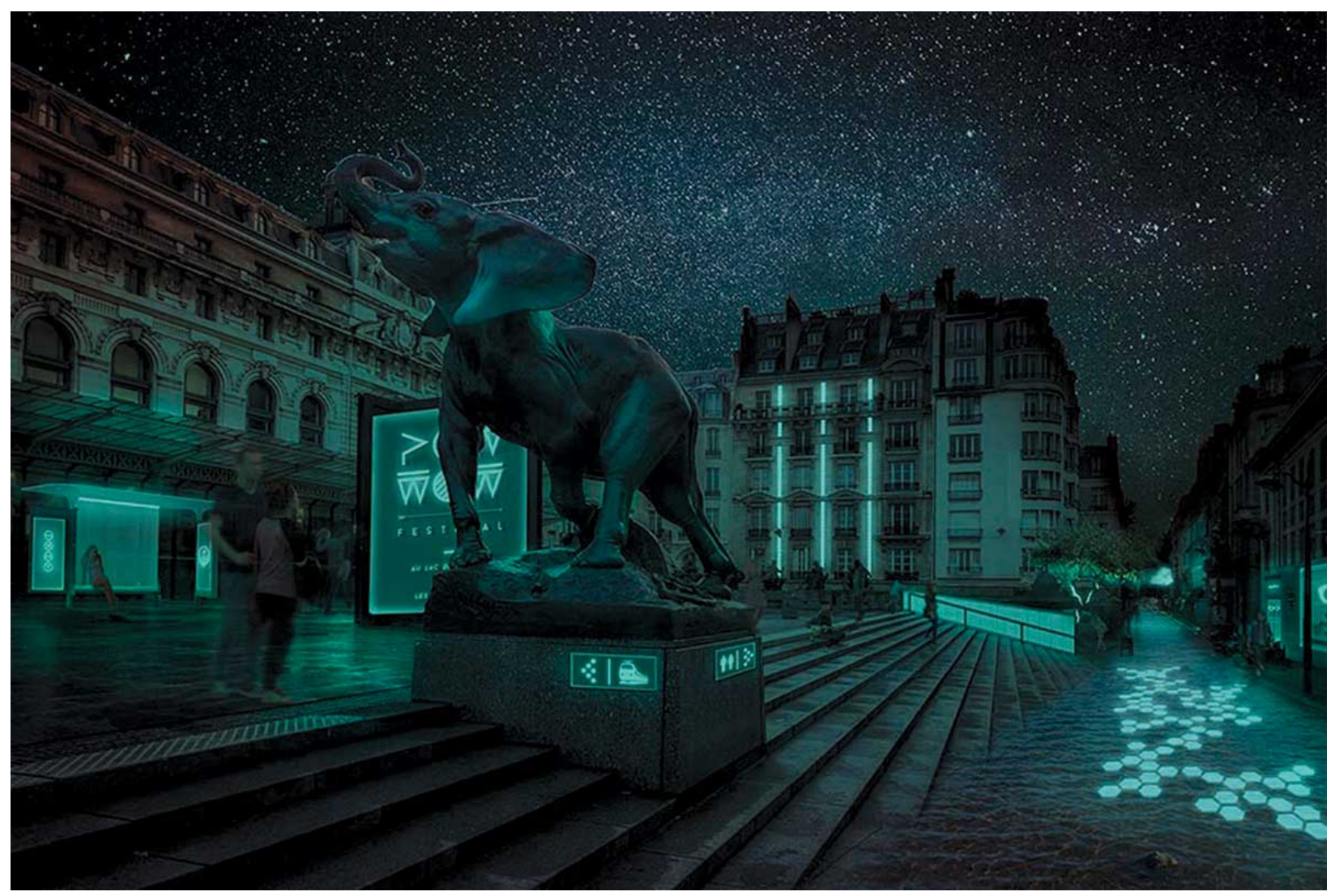

A speculative image of glowing units by French start-up Glowee, who are working on engineering marine micro-organisms for light sources. Credit: Glowee. 
Biology isn't inherently good, safe, or kind. By imagining that biotechnology will help solve sociopolitical problems, we risk missing the opportunity to identify big, systemic changes that may be a more appropriate fix. Making stuff with biological systems simply for the sake of making stuff will likely lead to a future similar to the present, with the same ecological and social issues. That approach exposes a limit of imagination of what biodesign could be used for. Asking how do we move forward means contemplating what we want forward to mean. How do we imagine other biological futures? Do the futures we want to see justify humans designing other living things? Since we are part of nature, and can't live without it, what relationship with nature do we want, and what will we get? What relationship with other humans would those futures enable? Who should we ask? Who gets to ask? Can biology show us other ways to imagine?

\section{Other to Each Other}

For Other Biological Futures, we explore these questions and seek out other imaginations for biodesign. "Other" is a social condition contingent on difference to a dominant cultural hegemony. Visions are limited by the lack of diverse viewpoints and expertise from those imagining these futures, to those implementing them. From the experience of women working in science, to geopolitical imperialism, as we ask how biodesign could proliferate, it becomes urgent to ask: who and what is other? Otherness is a rich space in which to include ideas from alternative geographies, economic frameworks, histories, knowledge systems, languages, religious beliefs, moral codes, ethnicities, genders, and non-human lifeforms. Other can mean an outside perspective, but it can also be relative. In our individual practices working with scientists, we regularly experiment outside of conventional art and design methods to explore the social dimensions of biotechnology, and we often operate as outsiders inside our own fields.

For this issue, we have initiated a series of conversations, published serially, between practitioners who are other to each other, in their views, their disciplines, or their cultures. We asked scientists, engineers, artists, writers, historians, designers, curators, and more, inside and outside of biodesign, to identify other possible biological futures, and to think together about who or what is missing from the discussion. How might their questions offer different ways to think about biodesign's potential?

Colonisation emerges as a recurring theme in the conversations: biological, but also cultural, geographic, and economic. Biodesigners, whether scientists or designers, often culture colonies of organisms, such as bacteria, algae, or fungi. But the issue of colonisation-and its imperial relationship with nature and enduring legacies - needs articulation in biodesign. Biodesign may be rooted in a desire to challenge existing industrial paradigms, however as the conversations below reveal (listed in no particular order), we think it needs a more critical culture. 
Our first conversation begins with Rab Messina, a design journalist from Latin America. She argues that the trend of western biodesigners experimentally appropriating resources from their own bodies including blood, sweat, or the microbiome, is a manifestation of Western guilt at planetary damage wrought by colonisation. The idea of the Anthropocene is problematic since it blames all humans, regardless of how or where they live. Does fault lie with nations polluting the most, nations that have polluted the most overall, or with all those who fail to act today? Speaking with Dutch artist Arne Hendricks, whose ongoing research project proposes shrinking humans to fifty centimeters tall as a radical solution to sustainability, they open up valuable insight on each other's perspectives from across the colonial divide, especially towards relative perceptions of abundance and human well-being. 
Okafor, founder of Maker Faire Africa and curator of TEDGlobal Africa, whose work catalyses African innovation, and Jim Ajioka, a professor of synthetic biology at the University of Cambridge. His interest is in distributing emerging technology in the developing world, with projects including developing an arsenic biosensor with NGOs in Nepal, to Colorifix, a company developing more sustainable dyes. They suggest "contextualising technology" could encourage equity, and imagine new models of collaboration that could emerge.

How might non-western technological and cultural perspectives affect the way humans around the world think about, and potentially design, the non-living, living, or "semi-living"? Bio artist Ionat Zurr, co-founder of the art/science laboratory SymbioticA, at the University of Western Australia and art practice Tissue Culture and Art (TC\&A), considers this in conversation with Maholo Uchida, curator at Tokyo's museum of emerging technologies, the Miraikan, and expert on robots. Zurr has investigated the Golem myth, the Jewish story of creation of life from earth, in her work. Meanwhile, in Japan, as Uchida explains, Shinto animist beliefs draw different boundaries between living and non-living beings, providing other ways to think about our relationships with nature and design.

Indigenous peoples who prioritise living in symbiosis with the natural systems that surround them can reveal other ways of knowledge-making that do not privilege the anthropocentric view endemic in science today. The Hawaiian artist Ahilapalapa Rands and Hawaiian microbiologist and indigenous science educator Kiana Frank, based at the Pacific Biosciences Research Center, discuss other cultural models and approaches to ecological understanding that could inform new directions for biodesign.

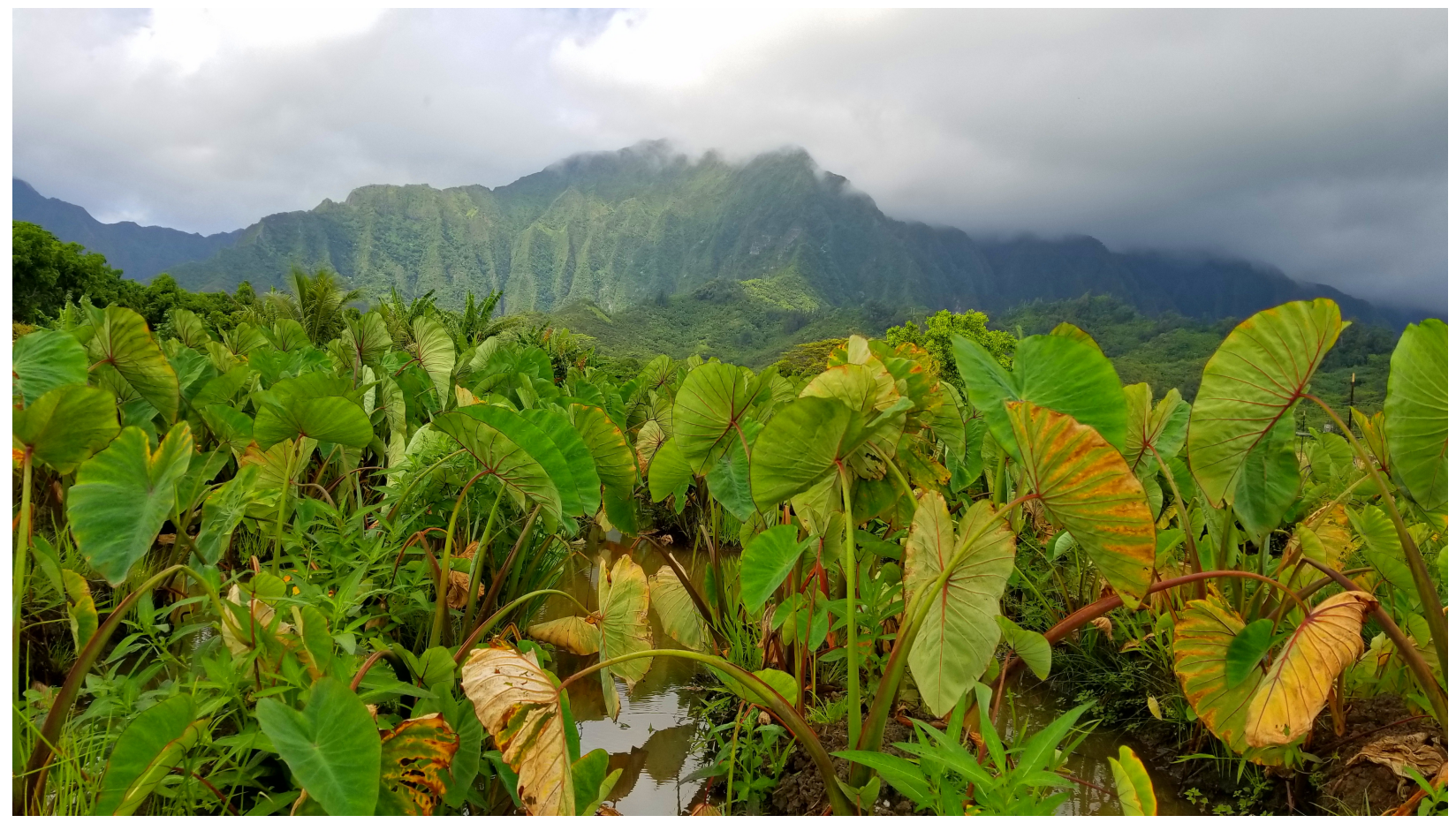

Field visit for research into restoring subsistence farming in Hawaii. Credit: Kiana Frank 
Synthetic biology brings together engineering and biology, but even those inside synthetic biology can feel like outsiders. While women are better represented in biological sciences than in other sciences, the engineering fields, including synthetic biology, are still male-dominated. Scientist Christina Agapakis is the Creative Director of Ginkgo Bioworks, a leading biotech start-up. Designer Suzanne Lee, is Chief Creative Officer of another biotech startup, Modern Meadow. As a scientist doing design, and a designer in science, both are women leaders in expanding industries. They discuss the challenges of creating new roles that bring a different understanding to what biological design could be.

Betul Kacar is an astrobiologist at the University of Arizona who uses paleogenomics to resurrect ancient genes and reconstruct evolutionary histories. Kacar describes her work as making "molecular time machines" as a way to explore common ancestors and try to rebuild lost histories. Author and film director Ytasha Womack, an expert on afrofuturism, uses fiction to enable new futures. In her stories, she use time machines to allow new identities to emerge from histories. Guiding us across multiple pasts and futures, their conversation explodes possibility across time and space.

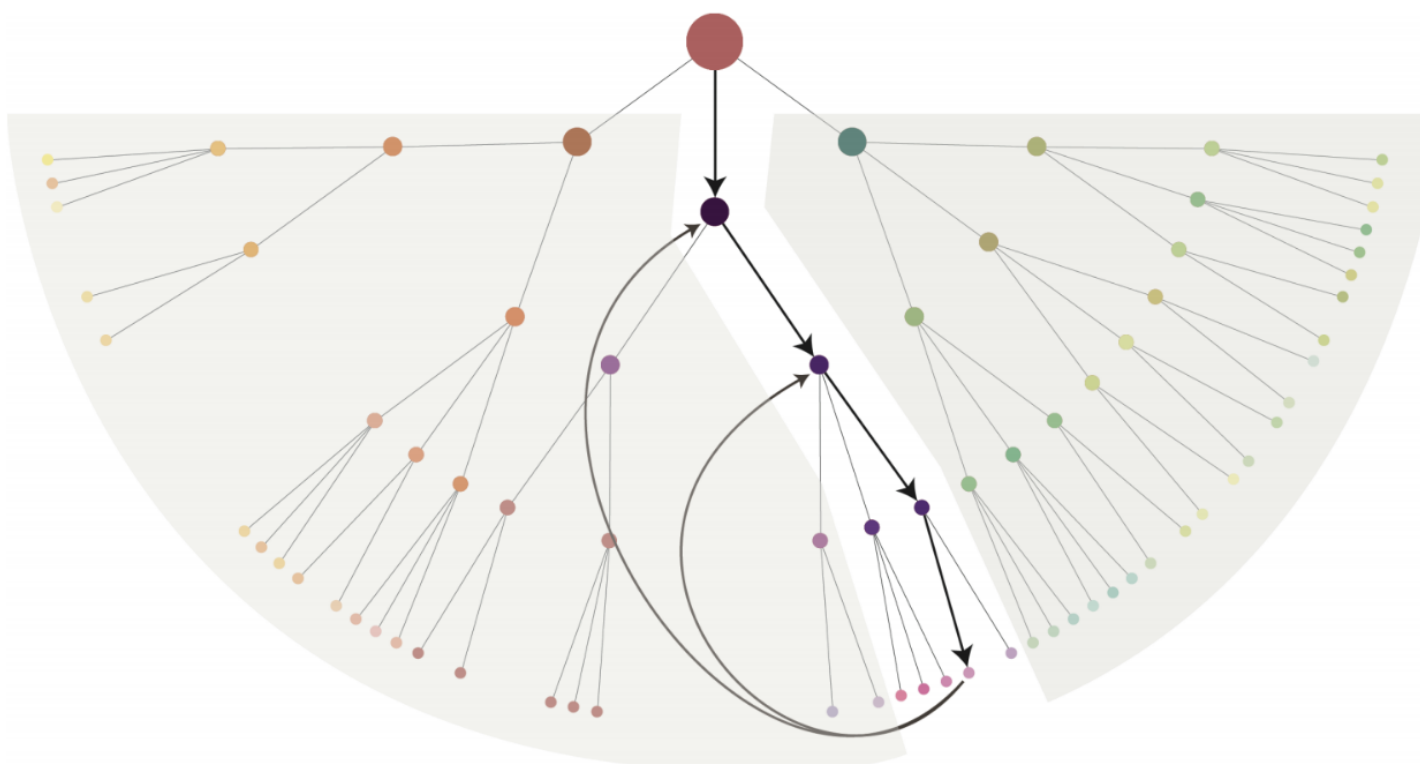

\section{Betul Kacar uses genetic engineering to experimentally replay evolutionary histories of molecules, as shown in this hypothetical scheme for a protein. Credit: Betul Kacar.}

Kacar observes what already exists by reconstructing the past in the present, while Womack builds futures to provide further insights into life's possibility. By contrast, as he works to add extra letters to the genetic code, chemist Steve Benner, at the Foundation For Applied Molecular Evolution, is creating an alphabet for writing other biological futures. His conversation with historian of synthetic biology and astrobiology, Luis Campos, of the University of New Mexico, considers the social and scientific 
contingency of the biology we have, and how life elsewhere, on other planets, could be "other" already. Biology's possibility space reminds us that we can go beyond pragmatic reinvention of industrial processes. Instead, design, art, and fiction can provide other ways of thinking to help us to reimagine the world. If design can enable preferable futures, we first need to imagine what else is possible.

Our starting questions for defining "good" biodesign were: "Can biology do this process better?" and "How will it change things for the better?" So far, the conversations in Issue 4 of JoDS have identified more questions and a more nuanced understanding of biodesign, revealing the intersections of biology with contemporary concerns from globalism to environmental degradation. But are the kinds of futures we claim we want feasible, given the political climate emerging in advanced technological societies? Addressing difficult questions of equity, agency, ecology, and even the moral basis for what is deemed "good" demands a more radical shift: one that recognises the need for re-distributing power and recalibrating individual and collective motivations. Where could imagining other futures of biodesign have an impact? Politics, cultures, values, capital, scale, manufacturing paradigms, ethics, imaginaries, imagination, and the biology itself are drivers and barriers to futures different from the present. Opening up this issue helps us identify these.

We can also usefully think about specific cases highlighting those drivers and barriers. A bioprospector could find a wild-type microbe in her backyard soil that does the same thing as an engineered version, designed in a lab in Boston. But who determines the value of each? Does society measure greater value by the engineered version providing a more efficient industrial model, or through the societal benefits of "bio-artisans" working with wild-types that offer more agile, open-access production models, which promote local autonomy through cottage industries? The existence of patented, synthetic organisms could mean monopolised biology is already upon us, with those other models increasingly impossible to imagine, let alone realise.

Our intention is not to diminish current efforts to invent new processes or drop-in replacement commodities; our critique focuses on only pursuing this approach, limiting alternative futures. Other Biological Futures is a call for and, not or. If good biodesign today asks: "Can biology do this better? How will this change things for good?", then we propose a third question that addresses others: "For whom, or for which other species does this matter?"

Biology is adaptive; it offers many possible solutions that may be less efficient, but make it more robust. Similarly, there isn't necessarily one answer here. We are not suggesting definitive solutions, although the conversations in Issue 4 of JoDS do locate directions for exploration: new approaches to edibility, novel partnerships between research institutes across continents, alternative intellectual property models, innovative pedagogical efforts cutting across sectors and nations, and the importance of protecting the artists' social contract, not exploiting it for short-term commercial gain. 
Using generative conversations of those "other" to each other, which reach across continents, cultures, disciplines, and motivations to frame these questions, we look to uncover missing voices, especially those outside of US and European biodesign. JoDS is built on the MIT Media Lab's experimental PubPub platform, which supports commenting and revision. We hope to test how the issue can grow new ideas and conversations, disturbing the traditional academic journal paradigm. We ask our readers to help us identify new networks, modes of thinking, and create tools to expand them: we seek comments, suggestions for new conversations, and new essays. As the issue and the conversation evolves, we will add to this editorial.

Biology is the most distributed "technology" on the planet, creatively "solving problems" that we now have the tools to further optimise for human benefit. This anthropocentric view is endorsed in synthetic biology. But biology is not a technology; humans make technology, and we are made of biology. Biodesign tools like synthetic biology afford humans immense opportunities to re-shape our natural world. As those technologies converge with others, like artificial intelligence, humanity holds an unprecedented amount of power over our shared biological futures. Who gets to design life, and in what context?

Our imagination today is limited by today's imaginaries. While biodesign could better some production methods, we think it's more interesting to use biodesign to help us identify new, diverse, biological, ecological, social models that are more equitable for all biology, not just select humans and a few monoculture crops. The spaces we create may eventually be cannibalised by capital; nothing may change. But as these conversations remind us, biology need not exist in the form we know it. Other biologies are possible. That means other worlds are possible. We can, and must, continue to imagine life otherwise. We hope that this issue of JoDS opens up other biological futures. 